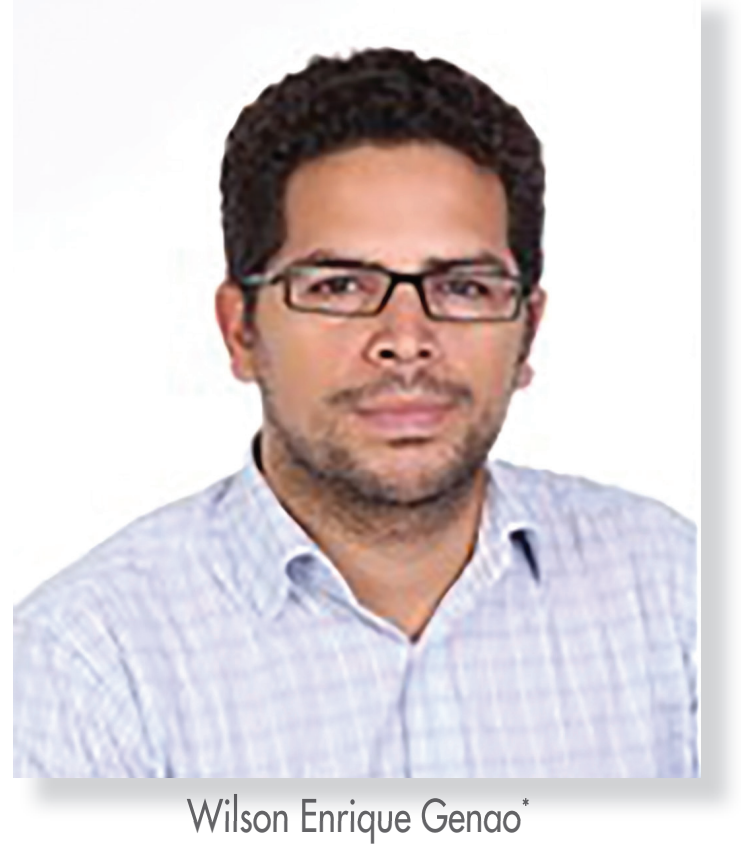

\title{
Reseña del libro \\ La utilidad de lo inútil. Manifiesto, de Nuccio Ordine
}

\section{Resumen}

La utilidad de lo inútil. Manifiesto, de la autoría de Nuccio Ordine es un libro publicado en el 2013 por la editorial Acantilado con traducción de Jordi Bayod. Critica la marginación de las disciplinas humanísticas, aborda la importancia de las humanidades en la formación de los ciudadanos y critica la mercantilización de la enseñanza.

\section{Palabras clave}

Humanidades, utilitarismo, estudios generales, mercantilización, saberes humanísticos

En las últimas décadas, escritores, filósofos y analistas sociales no han dejado de coincidir en plantear la marginación y pérdida de relevancia de las humanidades en los planes de estudios y en la inversión en educación que hacen los gobiernos de diversos países en Occidente. Las reformas educativas que se han implementado en muchos países han terminado relegando las humanidades sobre la base de un criterio educativo de rentabilidad o utilidad acorde a la tendencia expansiva y constante del capitalismo hacia el área de producción del saber para que este se organice de acuerdo con parámetros propiamente capitalistas.

El "adiestramiento técnico y la enseñanza puramente utilitaria de aplicaciones del conocimiento científico ocupan cada vez más exclusivamente los programas lectivos de todos los niveles formativos en una gran mayoría de los países del mundo". (Cordua, 2012, p. 7)

Sin embargo, existen universidades que están haciendo un esfuerzo por fortalecer las áreas de humanidades, como es el caso de la Pontificia Universidad Católica Madre y Maestra cuya naturaleza como institución se inspira en el humanismo cristiano. Fruto de un proceso de reflexión, revisión y reforma del Ciclo Básico, ha empezado a impartir de forma escalonada a partir del año académico 2016-2017 los estudios generales cuya "intención apunta al desarrollo holístico de la persona, a situar al joven dentro de una cosmovisión

*Wilson Enrique Genao: Director del Departamento de Humanidades en el Campus Santo Tomás de Aquino. Maestría en Historia Aplicada a la educación por la Pontificia Universidad Católica Madre y Maestra. Diplomado en Pedagogía Universitaria por la Pontificia Universidad Católica Madre y Maestra (PUCMM). Diplomado en Alfabetización Académica por la Pontificia Universidad Católica Madre y Maestra (PUCMM). Para contactar el autor: wilsongenao@pucmm.edu.do 
que lo fortalezca internamente y a desarrollarlo como ciudadano" (PUCMM, 2016, p. 11). La aplicación de los estudios generales constituye un esfuerzo institucional por fortalecer los conocimientos humanísticos y la formación integral, en una sociedad que desecha lo inútil, desinteresado y gratuito, a cambio de aferrarse a la búsqueda de lo beneficioso y útil.

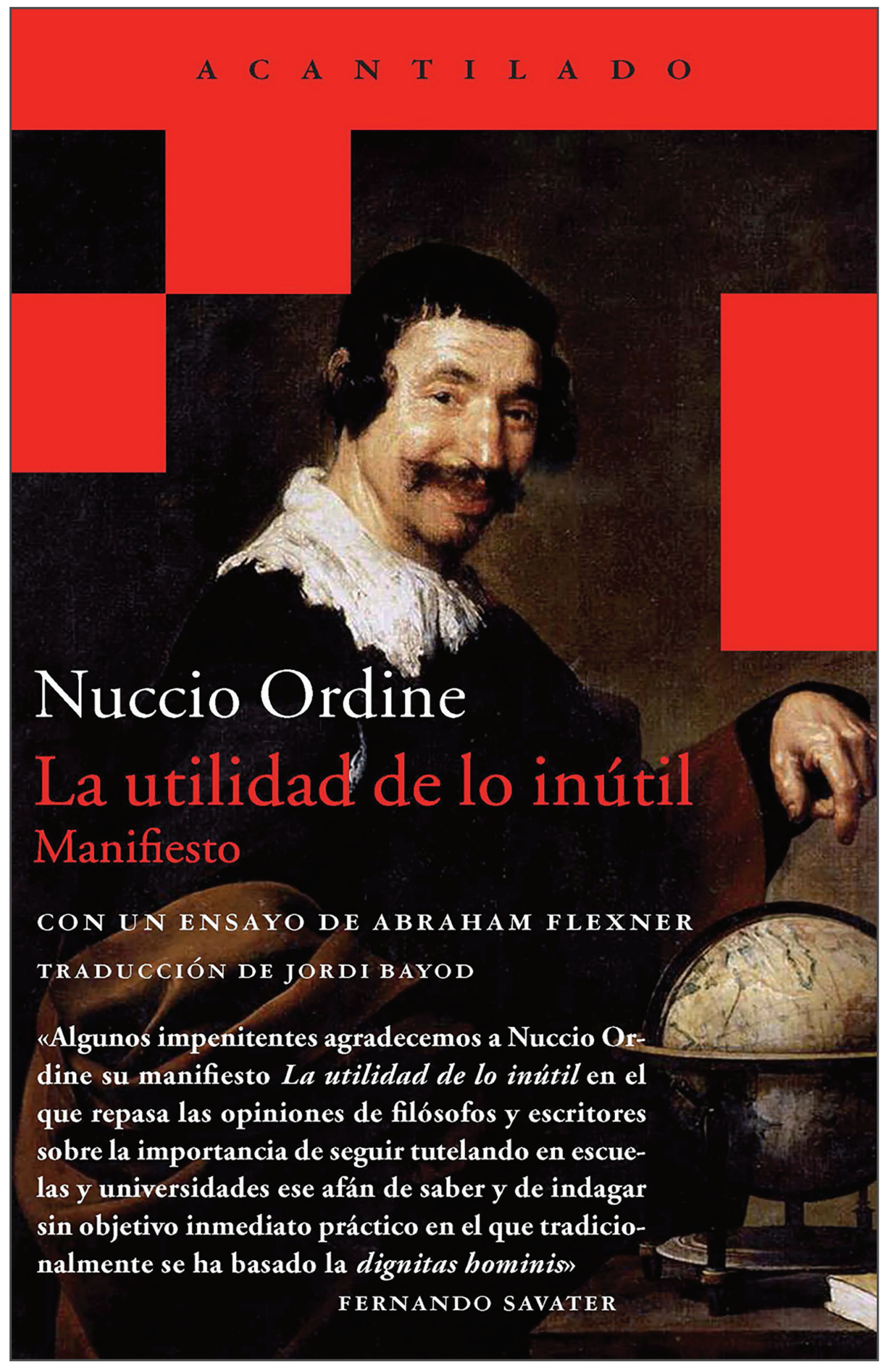

Diversos escritores y filósofos han alertado de las consecuencias que tiene para la sociedad que los saberes humanísticos pierdan el valor que deben tener en la formación de un profesional que no solo sea un experto en su carrera sino que como establece el Modelo Educativo de nuestra universidad sea un profesional, "con sentido ético y una conciencia crítica de la realidad, que propicien acciones a favor de la dignidad humana, que busquen la paz, que promueven la justicia social y la protección de la naturaleza" (PUCMM, 2011, p.12)

Uno de los autores más crítico contra la noción del utilitarismo de la sociedad que considera inútil los saberes humanísticos es Nuccio Ordine, escritor, filósofo y profesor en de Literatura italiana en la Universidad de la Calabria en Cosenza (Italia). $\mathrm{Ha}$ sido profesor visitante de centros como Yale, París IVSorbonne, CESR de Tours, IEA de París, el Warburg Institute o la Sociedad Max Planck de Berlín. Es uno de los mayores expertos contemporáneos de Giordano Bruno y del Renacimiento. 
Ordine ha publicado, entre muchos otros libros, un contundente manifiesto en defensa de las humanidades titulado La utilidad de lo inútil (Acantilado, Quaderns Crema, 2013) el cual es el objeto de esta reseña. La obra se divide en tres partes, con una amplia introducción y un ensayo como apéndice de Abraham Flexner de 1937 , publicado de nuevo en 1939 con algunos añadidos.

En La utilidad de lo inútil, Ordine realiza una reflexión crítica de la sociedad utilitarista y aborda la problemática de las humanidades en la sociedad cientificista que margina los saberes humanísticos al considerar que carecen de beneficios prácticos para la sociedad.

El autor defiende la tesis de que la literatura, la filosofía y otros saberes humanísticos y científicos no son inútiles, como cabría deducir de su progresivo destierro en los planes educativos y presupuestos ministeriales, sino que son necesarios e imprescindibles para la humanidad. El interés del autor no es sostener el valor de las Humanidades y del sentido común en desmedro de la ciencia, la técnica o la competitividad, sino que ellas tienen un valor en sí mismas y juegan un rol determinante en nuestra formación humana, ciudadana; en el desarrollo de nuestro espíritu crítico y al mismo tiempo compasivo, capaz de tomar en cuenta a esa humanidad que implica ser iguales y distintos.

En la parte introductoria el autor sitúa la realidad que viven las humanidades en el contexto del siglo XXI, reivindicando el hecho de que existen saberes que son fines en sí mismos y que -precisamente por su naturaleza gratuita y desinteresada, alejada de todo vínculo práctico y comercial- pueden ejercer un papel fundamental en el cultivo del espíritu y en el desarrollo civil y cultural de la humanidad. Ordine precisa el término de utilidad, afirmando que cuando aborda dicho concepto se refiere no sólo a los saberes humanísticos considerados inútiles al no producir beneficio, sino a todos los saberes cuyos fines se alejan de cualquier propósito utilitarista.

En la primera parte titulada "La útil inutilidad de la literatura", Ordine hace un recorrido histórico a través de numerosos autores de diversas áreas disciplinares. Toma argumentos de clérigos como Vincenzo Padula; poetas y escritores como Ovidio, Dante, Petrarca, Boccaccio, Cervantes, Shakespeare, Dickens, García Lorca, Márquez, y filósofos como Sócrates, Platón, Aristóteles, Kant, Michel Montaigne, Martin Heidegger y Paul Ricoeur, etc., de los cuales va tomando argumentos para valorar la utilidad de lo que a veces la sociedad entiende como inútil y para justificar su visión de la necesidad y utilidad de los saberes humanísticos en la formación de la persona y del profesional.

Frente a la lógica del utilitarismo, la obsesión por la ganancia y lo útil, valora la ilusión, los ideales, la gratuidad y asume las palabras de Heidegger el cual considera que el hombre moderno, que ya no tiene tiempo para detenerse en las cosas inútiles, está condenado a convertirse en una máquina sin alma. Prisionero de la necesidad, ya no está en condiciones de entender que lo útil puede transformarse en un peso inútil y agobiante. Se identifica con las palabras de Ítalo Calvin el cual valora las humanidades y la lectura de los clásicos con una perspectiva de valor en sí mismo. Citando a Calvo, considera que los clásicos mismos no se leen porque deban servir para algo: se leen tan sólo por el gusto de leerlos, por el placer de viajar con ellos, animados únicamente por el deseo de conocer y conocernos.

Ordine culmina la primera parte describiendo el estado de abandono de las humanidades afirmando que en el invierno de la conciencia que estamos viviendo a los saberes humanísticos y a la investigación científica sin utilitarismo alguno, les corresponde cada vez más la tarea de alimentar la esperanza, de transformar su inutilidad en un utilísimo instrumento de oposición, en un inmenso granero en el que puedan preservarse la memoria y los acontecimientos injustamente destinados al olvido. Lo que supone que las humanidades juegan un rol decisivo en la formación de ciudadanos críticos, reflexivos, con responsabilidad y compromiso social.

En los últimos años, en muchas universidades de diversos países se ha ido instalando una concepción que entiende que estas únicamente deben funcionar con los principios empresariales y deben orientarse con los postulados de rentabilidad, eficacia, eficiencia y competitividad propios de la economía de mercado. El impacto de esta visión ha generado consecuencias drásticas en el campo de las humanidades, aspecto que lo desarrolla Ordine en la segunda parte del libro titulada "La universidad-empresa y los estudiantesclientes". El autor analiza las consecuencias producidas por la lógica del beneficio en el campo de la educación, la investigación y las actividades culturales.

Ordine critica la situación de cómo en algunos países europeos de manera progresiva los institutos de secundaria y universidades se han trasformado en empresas. 
El autor considera que los estudiantes son considerados clientes, y dado que el cliente siempre tiene la razón, la calidad de la enseñanza merma en favor de la rapidez con la que se quiere conseguir un título.

El problema de la burocratización del profesorado es abordado a partir de la mercantilización de la educación y la cultura, donde prima la cantidad a la calidad. Ordine entiende que los profesores se transforman cada vez más en modestos burócratas al servicio de la gestión comercial de las empresas universitarias por lo cual sostiene que las escuelas y las universidades no pueden manejarse como empresas.

Privilegiar de manera exclusiva la profesionalización de los estudiantes significa perder de vista la dimensión universal de la función educativa de la enseñanza. En consecuencia, además de la formación disciplinar, el profesional debe formarse en lo humano, lo social, lo cultural y lo trascendente, visión compartida por la PUCMM y expresada en nuestro Modelo Educativo.

Frente a la situación de crisis y las medidas que se toman cada vez más tendentes a una menor financiación de las humanidades por su poca utilidad, Ordine afirma que en lugar de mermar el gasto en estas áreas, se debería duplicar, puesto que el conocimiento es quien hace libre a las personas, les otorga capacidad crítica y de reflexión.

Para justificar su defensa, asume los argumentos de varios pensadores, haciendo especial énfasis en el discurso de Víctor Hugo a la Asamblea Constituyente donde afirma que las crisis no se superan recortando los fondos para la cultura sino duplicándose y en John Henry Newman quien plantea una calurosa defensa del valor universal de la educación y considera como falsa la tesis según la cual solamente lo útil merece ser buscado, reafirmando la importancia del saber en sí.

El autor critica que cada día los clásicos y las humanidades ocupan un lugar cada vez más marginal en las escuelas y universidades. Entiende que no hay posibilidad de concebir ninguna forma de enseñanza sin los clásicos. Finaliza la segunda parte haciendo un llamado a esforzarse para salvar de la deriva utilitarista no sólo la ciencia, la escuela y la universidad, sino también todo lo que es cultura.

En la tercera parte titulada Poseer mata: Dignitas hominis, Amor, Verdad desarrolla la carga ilusoria de la posesión y sus efectos devastadores sobre la dignitas hominis. Ordine aborda los temas de la dignitas hominis, el amor y la verdad en clave humanística considerando los dos últimos como el terreno ideal donde la gratuidad y el desinterés pueden expresarse de la manera más auténtica.

La tercera parte culmina valorando la gratuidad, lo que la sociedad considera inútil y considerando que la dignitas hominis no puede medirse según el criterio de las riquezas poseídas ni se fundamenta en los valores vinculados al beneficio y la ganancia.

En la parte final como anexo, Ordine presenta el ensayo de Abraham Flexner de 1937, publicado de nuevo en 1939 con algunos añadidos, en el cual muestra de forma magistral que la ciencia tiene mucho que enseñarnos sobre la utilidad de lo inútil. Defiende la idea de que junto a los humanistas, también los científicos han desempeñado y desempeñan una función importantísima en la batalla contra la dictadura del beneficio, en defensa de la libertad y la gratuidad del conocimiento y la investigación.

En definitiva, frente a una sociedad en la que cada día se impone la dictadura del beneficio y la ganancia, que entiende que lo que no suponga una ganancia económica es inútil y por lo tanto no merece la pena perseguirlo y de que todo lo que no se pliega a la lógica mercantilista del lucro no merece el interés de la gente, ni el apoyo de las instituciones, es oportuno el debate que suscita esta obra de Ordine.

La utilidad de lo inútil que constituye un manifiesto intelectualmente provocador para el debate sobre el rol de las humanidades, esta oportuna obra reivindica la dignidad de lo inútil y la pasión por los saberes humanísticos en un momento en que la Universidad empieza a implementar los estudios generales.

\section{Referencias}

Cordua, C. (2012/mes). La crisis de las humanidades. Revista de filosofía, vol.68, 7-9.

PUCMM, (2011). Modelo Educativo, Santiago de los Caballeros, Editora Teófilo.

PUCMM, (2016). Núcleo del Plan de Estudios Generales. 